\title{
Solid variant of adenoid cystic carcinoma of oral cavity: A diagnostic difficulty in histopathological examination
}

\author{
Veenaa Venkatesh ${ }^{1}$, Priya Murugan ${ }^{2, *}$ \\ ${ }^{1}$ Associate Professor, ${ }^{2}$ Post Graduate (MD Pathology), Dept. of Pathology, Karpagam Faculty of Medical Science and Research, \\ Coimbatore, Tamil Nadu, India
}

*Corresponding Author: Priya Murugan

Email: drrajivpriya91@gmail.com

\begin{abstract}
Introduction: Adenoid cystic carcinoma (ACC) is a malignant tumor affecting mainly the salivary glands. It can also occur in other sites like breast and skin. It is important to diagnose adenoid cystic carcinoma at its early stage because this tumor is well known for its local recurrence and distant metastasis. This tumor accounts for about $1 \%$ of all head and neck malignancies and 6-10\% of all salivary gland neoplasms. Adenoid cystic carcinoma occurs in any salivary gland site, but approximately 50-60\% develop within minor salivary gland especially palate. The tumor is seen to arise from the pluripotent stem cell which gives rise to ductal epithelial and myoepithelial cells. Three patterns occur in ACC namely cribriform, tubular and solid. The cribriform pattern is the most common form and the solid pattern is the least common. However, in most cases combination of two or more patterns are seen. The solid variant of ACC has significant morphological and immunohistochemical overlap with a large range of tumors including others carcinoma and sarcoma.

Case Report: In this study, we describe three cases of oral cavity lesions with different clinical presentations. Histopathological examination was done and a diagnosis was made. Immunohistochemistry was further done to support the diagnosis.

Discussion: Solid variant of ACC was diagnosed on histopathological examination of all three cases. Solid variant of ACC may be misinterpreted for many other benign and malignant tumors, in oral cavity, because cribriform pattern which is seen in most cases of ACC is lacking in this variant. These three cases are presented here because of rarity and difficulties in diagnosis of this pattern of ACC exist in microscopic examination. These patients need to be treated with intensive therapy to avoid recurrence and further spread.
\end{abstract}

Keywords: Adenoid cystic carcinoma, Solid variant, Poor prognosis.

\section{Introduction}

Adenoid cystic carcinoma is an uncommon form of malignant salivary gland. Other sites of origin include trachea, lacrimal gland, breast, skin and vulva. ${ }^{1}$ Early lesions of ACC of oral cavity present as slowly growing painless masses. Advanced tumours present with pain and /or nerve paralysis. This tumour is notorious for its recurrence and metastasis. ${ }^{2}$ Lung is the most common site for metastasis, liver being the second most common. ${ }^{3-5}$ Most patients are diagnosed during the fifth or sixth decade. Specific etiology of this malignancy is unknown. However, inactivation of p53 tumour suppressor gene is seen in some cases of ACC. The diagnosis of ACC is made by histopathological examination of the biopsy or resected specimen of the lesion. Grossly, the tumor is usually a poorly circumscribed, unencapsulated firm mass with a size ranging from 1 to $8 \mathrm{~cm}$ in maximum dimension. Cut surface shows a solid grey white firm mass. Areas of necrosis and haemorrhage usually indicate high-grade transformation into dedifferentiated ACC.

Microscopically, the tumor is heterogenous and shows three patterns: ${ }^{6}$ cribriform, tubular and solid. Frequently, combination of more than one pattern exists. The cribriform pattern is the most common followed by tubular. The solid variant is very rare and indicates aggressive nature of the tumor. The cribriform pattern is composed of islands of basaloid cells surrounding cyst-like spaces forming a "swiss-cheese" pattern. These spaces are called pseudocysts because they donot represent true lamina. These spaces contain eosinophilic or basophilic PAS positive material. The second most common pattern is tubular pattern in which tumor cells are arranged in nests surrounded by eosinophilic hyalinized stroma. Well formed ductular structures lined by both inner epithelial and outer myoepithelial cell layers are seen and are more prominent than in cribriform pattern. The least common pattern is solid variant of ACC in which basaloid tumor cells are seen in aggregates. In this variant, cells are larger and show more nuclear pleomorphism, mitosis and necrosis. Occasional tubular structures may be seen among sheets of tumor cells. Histological grading of ACC is controversial. Table 1 shows different grading systems based on the percentage of solid component in the tumor. ${ }^{7}$

Table 1: Showing different grading systems of adenoid cystic carcinoma

\begin{tabular}{|l|c|c|}
\hline \multicolumn{1}{|c|}{ Perzin 1978 and Szanto 1984 } & Spiro 1992 & Van weert 2015 \\
\hline $\begin{array}{l}\text { Grade 1: Mostly tubular or cribriform } \\
\text { components, occasional solid component. }\end{array}$ & $\begin{array}{c}\text { Grade 1: Mostly tubular or cribriform } \\
\text { components, occasional solid component. }\end{array}$ & Solid component absent. \\
\hline $\begin{array}{l}\text { Grade 2: Predominantly cribriform } \\
\text { component or mixed <30\% solid component. }\end{array}$ & $\begin{array}{c}\text { Grade 2: Mixture of components with a solid } \\
\text { component of }>50 \% .\end{array}$ & Solid component present. \\
\hline $\begin{array}{l}\text { Grade 3: Marked predominantly of the solid } \\
\text { component }(>30 \%)\end{array}$ & Grade 3: Mostly / only solid component. & \\
\hline
\end{tabular}


In all three grading system, the solid type is considered a high grade tumor with poor prognosis. Intra-oral ACCs are more common in hard palate. Others less common intra-oral sites include lower lip, retromolar tonsillar region, sublingual gland, buccal mucosa and floor of mouth. Painless swelling is the most common symptom in ACC. Other symptoms include pain, paralysis and node enlargement. In this study, we report three cases of solid variant of adenoid cystic carcinoma of oral cavity, the early diagnosis of which is important for prompt treatment and prognostication.

\section{Case Report}

First case is a 54 year old female who presented to the ENT department with a small lesion in the floor of the mouth. CT scan was done which revealed an enhancing mass lesion in the floor of mouth with possible invasion of submandibular gland and cervical lymph nodes. CT chest showed small bilateral lung nodules possibly metastasis. An incisional biopsy was taken from the lesion in the floor of the mouth and the submandibular gland was also removed due to the pain complained by the patient in the region. Gross examination and histological findings of this case were analysed.

On gross examination, biopsy from the lesion in the floor of the mouth showed multiple linear grey white soft tissue bits altogether measuring $1 \times 0.5 \times 0.3 \mathrm{~cm}$. Entire tissue was embedded. Submandibular gland measured $3 \times 2 \times 1 \mathrm{~cm}$. Cut surface showed unremarkable parenchyma except for focal irregular grey white firm areas. Extensive sections were taken from submandibular gland (Fig. 1).

Microscopically, multiple sections studied from swelling floor of mouth showed fragments of tissue with an invasive malignant salivary gland tumor composed of cells arranged predominantly in solid pattern. Focal tubular and cribriform patterns were seen. The individual tumor cells showed clear cytoplasm and oval hyperchromatic nucleus. Mild to moderate nuclear pleomorphism was seen. The intervening areas showed myxoid stroma. No necrosis or mitosis identified (Fig. 2). Extensive multiple sections studied from left submandibular gland showed invasion by the above tumor through the outer margins into the periphery of the gland parenchyma. The other areas of the submandibular gland showed marked chronic inflammation. Perineural invasion of the tumor was also identified (Fig. 3).

The second case is a 70 year old male patient with a swelling in the left cheek region, who came to the cytology department for fine needle aspiration. The smears aspirated revealed clusters and scattered basaloid cells with irregular nuclear contours and anisonucleosis. A diagnosis of malignant minor salivary gland tumor was made. Subsequently the swelling was resected and sent for histopathological examination.

On gross examination, a well circumscribed mass with overlying skin was received measuring $2 \times 1 \times 1 \mathrm{~cm}$. Cut surface was grey white firm solid. No necrosis or haemorrhage identified. Entire tissue was embedded. Microscopically, multiple sections studied showed a poorly circumscribed tumor composed of basaloid cells arranged predominantly in solid pattern (>95\%). The cells showed scant cytoplasm and round to oval hyperchromatic nucleus. Intervening cystic spaces were seen. Basement membrane material between tumor cells similar to that seen in cylindroma, was noted. Moderate degree of nuclear pleomorphism and occasional mitosis were seen. Focal clear cells were seen. No perineural invasion was identified. Occasional tubules lined by tumor cells were noted. A diagnosis of ACC with predominant solid pattern was made (Fig. 4)

The third case was a 60 year old male, who presented with swelling in the buccal mucosa. An incisional biopsy was taken and sent for histopathological examination. Grossly multiple tiny linear tissue bits were received altogether measuring $0.5 \times 0.2 \mathrm{~cm}$. Entire tissue was embedded. Microscopically, multiple sections studied show tiny fragments of tissue with a tumour composed predominantly of solid sheets of cells with basaloid nucleus and scant cytoplasm. Moderate degree of nuclear pleomorphism is seen. Occasional myxoid areas were identified. A diagnosis of solid variant of adenoid cystic carcinoma was made (Fig. 5).

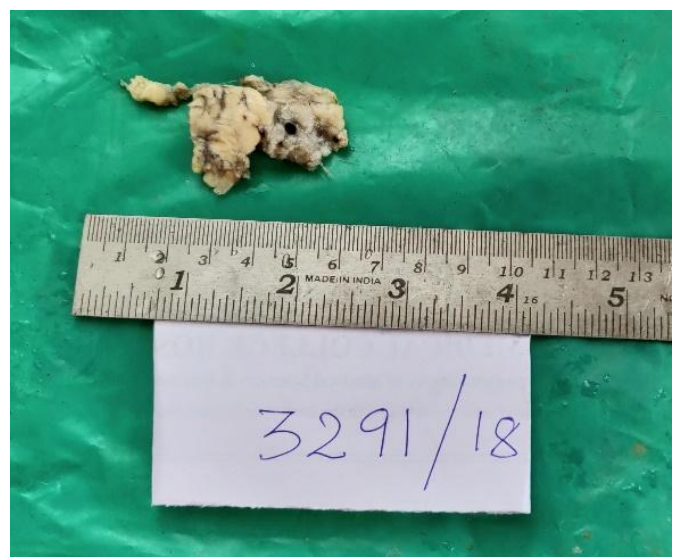

Fig. 1: Submandibular gland showing predominantly unremarkable parenchyma with focal irregular grey white areas

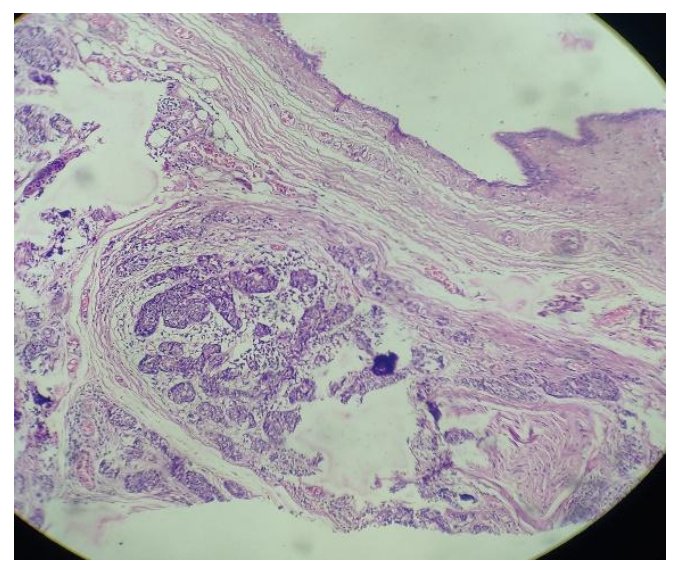

Fig. 2: Showing invasion of the submandibular glands parenchyma by the tumour. (H\&E 10X) 


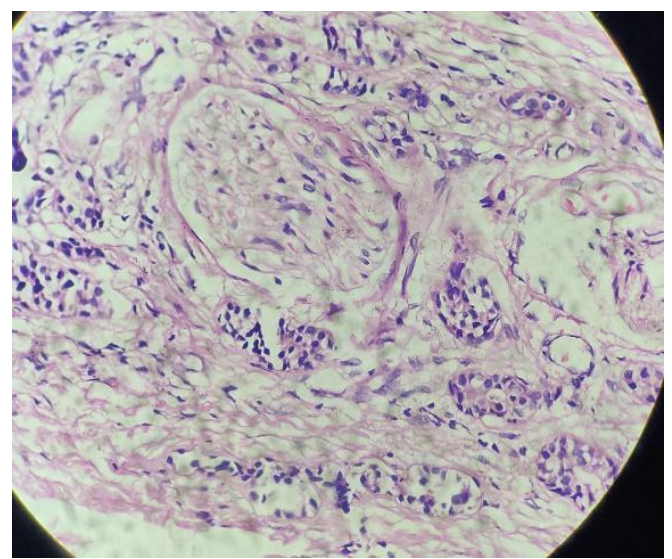

Fig. 3: Adenoid cystic carcinoma showing perineural invasion (H\&E 40X)

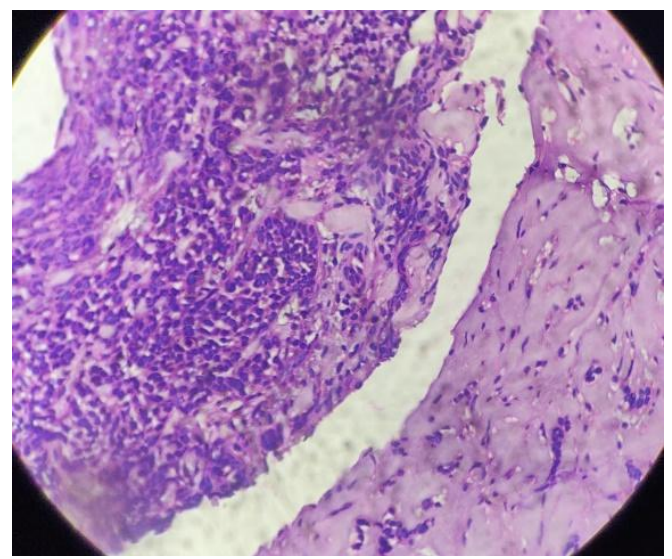

Fig. 4: Microscopy showing tumour cells in solid pattern in a myxoid stroma. (H\&E 40X)

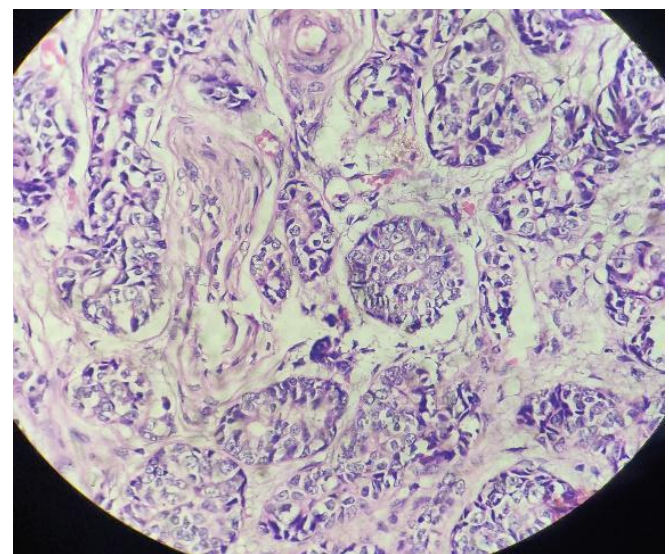

Fig. 5: Adenoid cystic carcinoma showing solid pattern of tumour cells. (H\&E 40X)

\section{Discussion}

ACC is a malignant tumor arising from salivary glands of the head and neck. Electron microscopically, it is found to arise from the cells that can differentiate into epithelial and myoepithelial cells. ACC arises from mucous secreting glands of the structures derived from foregut including parotid, submandibular, sublingual glands and from the mucous glands of paranasal sinuses and upper respiratory tract, ${ }^{8}$ ACC was first described by Theodar Billroth in 1859, when he named the tumor as cylindroma based on its histological features. ${ }^{10}$ It was then named as Baslioma, by krompecher in 1908, since the tumor was found to be analogous to the basal cell growths of the skin. Among the salivary gland tumors $50 \%$ are malignant. Of these $9 \%$ to $23 \%$ of tumors are seen in the oral cavity, followed by lacrimal gland, breast, skin, respiratory tract and cervix. These tumors have also been reported in the posterior body of mandible. ${ }^{11}$ ACC occur at any age and there is no sex predeliction. Different features are observed in this tumor. Usually, the tumor is not encapsulated but may be wellcircumscribed on gross examination. Three histological patterns have been described in this tumor: cribriform, tubular and solid. Of these patterns, solid variant is the most aggressive and high grade, and has a recurrence rate of $100 \%$ when compared to tubular and cribriform types in which $50-80 \%$ recurrences occur. Solid variant is also associated with worst prognosis, especially in cases of delayed diagnosis and distant metastasis. The differential diagnosis to be included are polymorphous low grade adenocarcinoma (PLGA), salivary duct carcinoma and basaloid squamous cell carcinoma (BSC). In PLGA, there is a polymorphous architecture with papillary growth, glandular structures and single cell infiltration. Basophilic pools of glycosaminoglycans are seen in ACC, but not seen in PLGA. The cytology of cells in PLGA also vary from those ACC. PLGA cells are bland with vesicular nuclei whereas ACC cells show hyperchromatic nuclei and mitosis. ${ }^{12}$ Salivary duct carcinoma is characterized by comedonecrosis. BSC should be distinguished from ACC especially in intra-oral region. ${ }^{13}$ The presence of squamous cell carcinoma insitu and dysplasia and focal keratinization are helpful distinguishing features, seen in BSC. ${ }^{6}$ Prognosis of ACC differs in different patterns; cribriform and tubular types have good prognosis. Solid pattern of ACC is considered as poorly differentiated and has the worst prognosis. ${ }^{14,15}$ Perineural invasion is a common feature in ACC. ${ }^{16}$ This tumor can invade into adjacent bony structures, causing osseous destruction. The 5 year survival rate is low in solid variant of ACC about $75 \%$. The patients with this pattern have aggressive nature and should be kept under close follow up. ${ }^{17}$

These cases are presented here because of the rarity and solid variant of ACC is important to be diagnosed due to its difficulty in recognition of histological features. Prolonged close follow up of these patients is needed to detect recurrences and metastasis.

\section{Conflict of Interest: None.}

\section{References}

1. Ben Salha I, Bhide S, Mourtzoukou D, Fisher C, Thway K. Solid Variant of Adenoid Cystic Carcinoma: Difficulties in Diagnostic Recognition. Int J Surg Pathol. 2016;24(5):419424. 
2. Marx RE, Stern D. Oral and Maxillofacial Pathology, a Rational for Diagnosis and Management. Chicago: Quintessence; 2002. pp. 550-553.

3. Triantafillidou K, Dimitrakopoulos J, Iordanidis F, Koufogiannis D. Management of adenoid cystic carcinoma of minor salivary glands. J Oral Maxillofac Surg. 2006;64:11141120.

4. Li Q, Xu T, Gao J, Ye W, Gu M, Hu W, Wang F, Cai X. Surgery alone provides long-term survival rates comparable to those of surgery plus postoperative radiotherapy for patients with adenoid cystic carcinoma of the palate. Oral Oncol. 2011;47:170-173. doi: 10.1016/j.oraloncology.2010.12.005.

5. Singh SG, Jain J, Pathak S, Singh KT. Adenoid cystic carcinoma of buccal mucosa. J Maxillofac Oral Surg. 2010;9(3):273-276. doi: 10.1007/s12663-010-0086-8.

6. Srivastava AC, Barpande SR, Bhavthankar JD, Mandale MS. Adenoid cystic carcinoma of palate: Report of a solid variant. $J$ Oral Maxillofac Pathol. 2018;22(Suppl 1):S65-S68.

7. van Weert $S$, van der Waal I, Witte BI, Leemans CR, Bloemena E. Histopathological grading of adenoid cystic carcinoma of the head and neck: analysis of currently used grading systems and proposal for a simplified grading scheme. Oral Oncol. 2015;51(1):71-76.

8. Bradley PJ. Adenoid cystic carcinoma of the head and neck: A review. Curr Opin Otolaryngol Head Neck Surg. 2004;12:127-132.

9. Balamucki CJ, Amdur RJ, Werning JW, Vaysberg M, Morris CG, Kirwan JM, et al. Adenoid cystic carcinoma of the head and neck. Am J Otolaryngol. 2012;33:510-518.

10. Lucas RB. Pathology of Tumors of the Oral Tissues. 4th ed. London: Churchill Livingstone; 1998. pp. 330-5.
11. Vipul Garg, Swati Roy, Kaveri Surya Khanna, Preeti Sethi Bakshi, Isha Chauhan. Indian J Otolaryngol Head Neck Surg. 2016;68(3):370-373.

12. Chundru NS, Amudala R, Thankappan P, Nagaraju CD. Adenoid cystic carcinoma of palate: A case report and review of literature. Dent Res J (Isfahan). 2013;10:274-278.

13. Nagao K, Matsuzaki O, Saiga H, Sugano I, Shigematsu H, Kaneko T, et al. Histopathologic studies of basal cell adenoma of the parotid gland. Cancer. 1982;50:736-745.

14. Neville BW, Damm DD, Allen CM, Bouquot JF. Salivary gland pathology. In: Neville BW, Damm DD, Allen CM, Bouquot JF, editors. Oral and maxillofacial pathology. Philadelphia: W.B. Saunders; 2002. pp. 389-496.

15. Perzin $\mathrm{KH}$, Gullane P, Clairmont AC. Adenoid cystic carcinomas arising in salivary glands: a correlation of histologic features and clinical course. Cancer. 1978;42:265282. doi: 10.1002/1097-0142(197807)42:1<265::AIDCNCR2820420141>3.0.CO;2-Z

16. Gondivkar SM, Gadbail AR, Chole R, Parikh RV. Adenoid cystic carcinoma: a rare clinical entity and literature review. Oral Oncol. 2011;47:31-36.

17. Pushpanjali M, Sujata DN, Subramanyam SB, Jyothsna M. Adenoid cystic carcinoma: An unusual presentation. J Oral Maxillofac Pathol. 2014;18:286-290.

How to cite this article: Venkatesh V, Murugan P. Solid variant of adenoid cystic carcinoma of oral cavity: A diagnostic difficulty in histopathological examination. J Oral Med, Oral Surg, Oral Pathol, Oral Radiol. 2018;4(4):186-189. 